\title{
Complete genome sequence of Olsenella uli type strain (VPI D76D-27C $C^{\top}$ )
}

\author{
Markus Göker ${ }^{1}$, Brittany Held ${ }^{3}$, Susan Lucas ${ }^{2}$, Matt Nolan², Montri Yasawong ${ }^{6}$, Tijana \\ Glavina Del Rio ${ }^{2}$, Hope Tice ${ }^{2}$, Jan-Fang Cheng ${ }^{2}$, David Bruce ${ }^{2,3}$, John C. Detter ${ }^{3}$, Roxanne \\ Tapia $^{3}$, Cliff Han' ${ }^{3}$, Lynne Goodwin ${ }^{3}$, Sam Pitluck², Konstantinos Liolios ${ }^{2}$, Natalia Ivanova ${ }^{2}$, \\ Konstantinos Mavromatis ${ }^{2}$, Natalia Mikhailova ${ }^{2}$, Amrita Pati ${ }^{2}$, Amy Chen ${ }^{4}$, Krishna \\ Palaniappan $^{4}$, Miriam Land ${ }^{2,5}$, Loren Hauser ${ }^{2,5}$, Yun-Juan Chang ${ }^{2,5}$, Cynthia D. Jeffries ${ }^{2,5}$, \\ Manfred Rohde ${ }^{6}$, Johannes Sikorski ${ }^{1}$, Rüdiger Pukall ${ }^{1}$, Tanja Woyke ${ }^{2}$, James Bristow ${ }^{2}$, \\ Jonathan A. Eisen ${ }^{2,7}$, Victor Markowitz ${ }^{4}$, Philip Hugenholtz ${ }^{2}$, Nikos C. Kyrpides ${ }^{2}$, and Hans- \\ Peter Klenk ${ }^{1}$, and Alla Lapidus ${ }^{2 *}$ \\ ${ }^{1}$ DSMZ - German Collection of Microorganisms and Cell Cultures GmbH, Braunschweig, \\ Germany \\ ${ }^{2}$ DOE Joint Genome Institute, Walnut Creek, California, USA \\ ${ }^{3}$ Los Alamos National Laboratory, Bioscience Division, Los Alamos, New Mexico, USA \\ ${ }^{4}$ Biological Data Management and Technology Center, Lawrence Berkeley National \\ Laboratory, Berkeley, California, USA \\ ${ }^{5}$ Oak Ridge National Laboratory, Oak Ridge, Tennessee, USA \\ ${ }^{6} \mathrm{HZI}$ - Helmholtz Centre for Infection Research, Braunschweig, Germany \\ ${ }^{7}$ University of California Davis Genome Center, Davis, California, USA \\ *Corresponding author: Alla Lapidus
}

Keywords: microaerotolerant anaerobe, human gingival crevices, primary endodontic infections, Coriobacteriaceae, GEBA

Olsenella uli (Olsen et al. 1991) Dewhirst et al. 2001 is the type species of the genus Olsenella, which belongs to the actinobacterial family Coriobacteriaceae. The species is of interest because it is frequently isolated from dental plaque in periodontitis patients and can cause primary endodontic infection. The species is a Gram-positive, non-motile and nonsporulating bacterium. The strain described in this study was isolated from human gingival crevices. This is the first completed sequence of the genus Olsenella and the fifth sequence from a member of the family Coriobacteriaceae. The 2,051,896 bp long genome with its 1,795 protein-coding and 55 RNA genes is a part of the Genomic Encyclopedia of Bacteria and Archaea project.

\section{Introduction}

Strain VPI D76D-27C (= DSM 7084 = ATCC 49627

$=$ JCM 12494) is the type strain of the species Olsenella uli, which is the type species of the genus Olsenella [1]. Currently, Olsenella is one out of thirteen genera in the family Coriobacteriaceae [2-4]. This strain was first described in 1991 by Olsen as 'Lactobacillus uli' [1]. Based on 16S rRNA gene sequence divergence and the presence of unique phenotypic characters, the strain was transferred to the new genus Olsenella as $O$. uli. A second novel species, O. profusa was also described [5]. More recently, a third species, 'O. umbonata', was described but is not yet validly published [6].The genus is named in honor of Ingar Olsen, a contemporary Norwegian microbiologist, who first described ' $L$. uli'. The species epithet 'uli' means 'of the gum'. Periradicular diseases are arguably among the most common human inflammatory diseases [7], which are often the result of microbial infection of the root canal [8]. Olsenella species, particularly $O$. uli, are common members of the microbiota associated with primary endodontic infection. $O$. uli has been found to predominate over other Gram-positive rods, (e.g., Atopobium parvulum) [9] in root canal samples taken after chemomechanical preparation and intracanal me- 
dication, suggesting that this species can resist intracanal disinfection measures and thus may be involved in persistent infections [10,11]. Here we present a summary classification and a set of features for 0 . uli VPI D76D-27CT, together with the description of the complete genomic sequencing and annotation.

\section{Classification and features}

Strains from the genus Olsenella are found in human oral cavity and likely in bovine rumen [1]. Strain VPI D76D-27C ${ }^{\mathrm{T}}$ was isolated from either human gingival crevices or periodontal pockets [1]. The 16S rRNA gene sequence of VPI D76D-27C ${ }^{\mathrm{T}}$ is 97\% identical to the cultivable strains N13-17 (AY880046) and S13-10 (AY880047). These strains were isolated from a 63-year old male patient with oral squamous-cell carcinoma [12]. Two other uncultured clone sequences with 100\% 16S rRNA gene sequence identity to strain VPI D76D-27CT were reported at the Genbank database (status July 2010) [13]. These were clone OPEN_ROOT_17 (FJ982973), isolated from human root canal, and clone BS34 (AY244985) from cow rumen. The 16S rRNA gene of strain VPI D76D-27C ${ }^{\mathrm{T}}$ shares 96.7$96.8 \%$ sequence identity with the sequences of the type strains from the other members of the genus Olsenella [14], whereas the other type strains from the family Coriobacteriaceae share 87.3 to $96.7 \%$ sequence identity [14]. No phylotypes from environmental screenings or genomic surveys could be linked to the species $O$. uli or to the genus Olsenella, indicating a rather rare occurrence of these in the habitats screened thus far (as of July 2010).
The cells of strain VPI D76D-27C $\mathrm{C}^{\mathrm{T}}$ are nonmotile (Table 1), Gram-positive rods that occur singly, in pairs, and in short chains (Figure 1) [1]. The central part of the cell may swell; particularly when grown on solid medium. Strain VPI D76D-27CT is microaerotolerant to anaerobic [6] with an optimal growth temperature is $37^{\circ} \mathrm{C}$ [1]. Colonies on brain heart blood agar are one to two $\mathrm{mm}$ in diameter, raised or low convex, entire, and translucent to transparent after five days of anaerobic incubation at $37^{\circ} \mathrm{C}$ [1]. The cells are unable to grow on media with $6.5 \% \mathrm{w} / \mathrm{v}$ of $\mathrm{NaCl}$. Growth is stimulated by Tween $80(0.02 \% \mathrm{v} / \mathrm{v})$. Strain VPI D76D-27C $\mathrm{C}^{\mathrm{T}}$ is able to ferment glycogen, trehalose and starch. Fermentation products from glucose are lactic, acetic, formic and occasionally trace amounts of succinic acid. Lactic acid is a major product of the strain VPI D76D-27C ${ }^{\mathrm{T}}$ [1], a feature which was suspected to be important in inflammatory processes of endodontic infections $[1,19]$. There is little or no gas detected in agar deeps during cell growth. Hydrogen and indole are not produced. Reactions are negative for bile-esculin, DNase and hippurate hydrolysis. This strain does not ferment amygdalin, erythriol, esculin, glycerol, inositol, mannitol, melezitose, melibiose, raffinose, rhamnose, sorbitol and xylose. Acid is produced from fructose, glucose, maltose, mannose, salicin, and sucrose [1]. Strain VPI D76D-27C ${ }^{\mathrm{T}}$ does not liquefy gelatin, does not digest meat, does not produce indole, and does not reduce nitrate [1]. It is negative for bile-esculin, DNase, hippurate hydrolysis and catalase activity. However, strain VPI D76D-27CT hydrolyses esculin and produces ammonia from arginine [1].

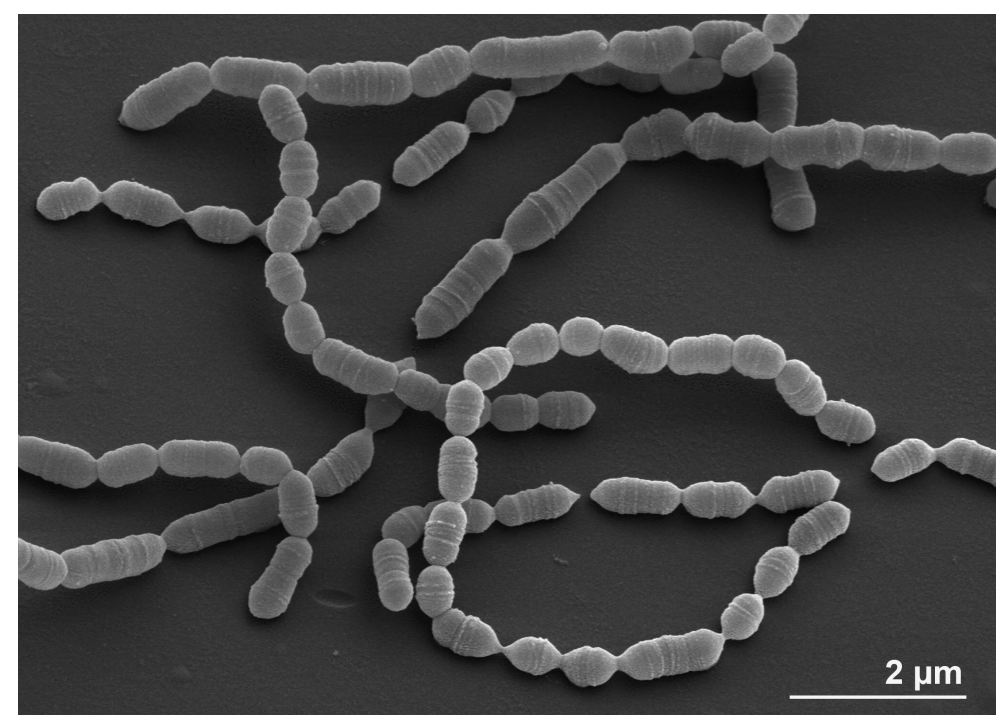

Figure 1. Scanning electron micrograph of O. uli VPI D76D-27C 


\section{Chemotaxonomy}

Strain VPI D76D-27C ${ }^{\mathrm{T}}$ possesses a peptidoglycan type of A4ß based on L-Orn-D-Asp [23]. The major cellular fatty acids of strain VPI D76D-27C ${ }^{\mathrm{T}}$ (FAME: fatty acid methyl ester; DMA: dimethylacetyl), when grown in peptone-yeast extractglucose-Tween 80 broth, are $\mathrm{C}_{18: 1}$ cis 9 (32.1\%, FAME), $C_{18: 1}\left(19.9 \%\right.$, DMA), $C_{10: 0}(10.1 \%, F A M E)$, $\mathrm{C}_{17: 1}$ cis8 (6.9\%, FAME), $\mathrm{C}_{18: 1} \mathrm{c} 11 / \mathrm{t} 9 / \mathrm{t} 6$ (5.3\%, FAME), $\mathrm{C}_{16: 1}$ cis 9 (4.8\%, FAME), $\mathrm{C}_{16: 0}(4.0 \%$, DMA), $\mathrm{C}_{18: 1}$ cis11 (3.6\%, DMA), $\mathrm{C}_{14: 0}$ (3.1\%, FAME), $\mathrm{C}_{16: 0}$ (2.8\%, FAME) and $\mathrm{C}_{12: 0}$ (2.6\%, FAME) [1]. More recent data show a somewhat different fatty acid pattern, which is characterized by a large proportion of unbranched fatty acids $\left(\mathrm{C}_{18: 0}, 31-50 \%\right)$ and a quite large proportion of polyunsaturated fatty acids $\left(\mathrm{C}_{18: 2}\right.$ cis-9, cis-12; 5.6-8.4\%). Presumably, this difference may be attributed to the different growth medium, which is described to be M2 liquid medium containing clarified rumen fluid [6].

Figure 2 shows the phylogenetic neighborhood of o. uli VPI D76D-27C in a $16 \mathrm{~S}$ rRNA based tree. The sequence of the unique $16 \mathrm{~S}$ rRNA gene is identical with the previously published sequence generated from ATCC 49627 (AF292373).

\section{Genome sequencing and annotation Genome project history}

This organism was selected for sequencing on the basis of its phylogenetic position [32], and is part of the Genomic Encyclopedia of Bacteria and Archaea project [33]. The genome project is deposited in the Genome OnLine Database [29] and the complete genome sequence is deposited in GenBank. Sequencing, finishing and annotation were performed by the DOE Joint Genome Institute (JGI). A summary of the project information is shown in Table 2.

\section{Growth conditions and DNA isolation}

O. uli VPI D76D-27CT, DSM 3776, was grown in medium 104 (PYG modified medium) [34] at $37^{\circ} \mathrm{C}$ under strictly anaerobic conditions. DNA was isolated from $0.5-1 \mathrm{~g}$ of cell paste using MasterPure Gram Positive DNA Purification Kit (Epicentre MGP04100) following the standard protocol as recommended by the manufacturer, with modification st/LALM for cell lysis as described in [33].

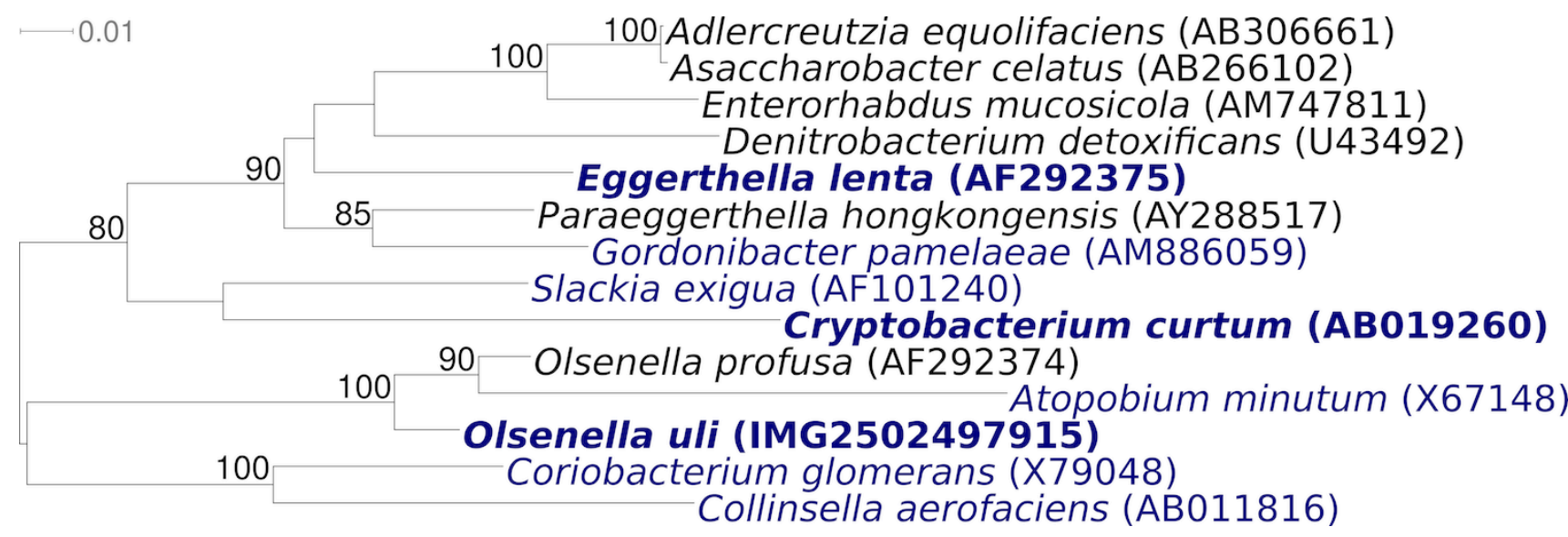

Figure 2. Phylogenetic tree highlighting the position of O. uli VPI D76D-27C $\mathrm{C}^{\top}$ relative to the type strains within the genus and the type strains of the other genera within the family Coriobacteriaceae. The trees were inferred from 1,408 aligned characters [24,25] of the 16S rRNA gene sequence under the maximum likelihood criterion [26] and as far as possible (note: Olsenella is paraphyletic in this tree) rooted in accordance with the current taxonomy [27]. The branches are scaled in terms of the expected number of substitutions per site. Numbers above branches are support values from 250 bootstrap replicates [28] if larger than 60\%. Lineages with type strain genome sequencing projects registered in GOLD [29] are shown in blue, published genomes in bold [30,31]. Adding the $16 \mathrm{~S}$ rRNA sequence of the type strain of the not yet validly published species 'Olsenella umbonata' (FN178463) to the tree (data not shown) did not change the overall arrangement; 'O. umbonata' appeared within the grade between $O$. uli and $O$. profusa. 
Table 1. Classification and general features of $O$. uli VPI D76D-27C $\mathrm{C}^{\top}$ according to the MIGS recommendations [15].

\begin{tabular}{|c|c|c|c|}
\hline MIGS ID & Property & Term & Evidence code \\
\hline & \multirow{9}{*}{ Current classification } & Domain Bacteria & TAS [16] \\
\hline & & Phylum Actinobacteria & TAS [17] \\
\hline & & Class Actinobacteria & TAS $[3,4]$ \\
\hline & & Subclass Coriobacteridae & TAS $[3,4]$ \\
\hline & & Order Coriobacteriales & TAS $[3,4]$ \\
\hline & & Suborder Coriobacterineae & TAS $[3,18]$ \\
\hline & & Family Coriobacteriaceae & TAS $[3,4]$ \\
\hline & & Genus Olsenella & TAS $[1,5]$ \\
\hline & & Type strain VPI D76D-27C & TAS $[1,5]$ \\
\hline & Gram stain & positive & TAS [1] \\
\hline & Cell shape & $\begin{array}{l}\text { small-elliptical rod that occur singly, in pairs } \\
\text { or short chains }\end{array}$ & TAS [1] \\
\hline & Motility & none & TAS [1] \\
\hline & Sporulation & none & TAS [1] \\
\hline & Temperature range & $37^{\circ} \mathrm{C}-45^{\circ} \mathrm{C}$ & NAS \\
\hline & Optimum temperature & $37^{\circ} \mathrm{C}$ & NAS \\
\hline & Salinity & $<6.5 \% \mathrm{NaCl}$ & TAS [1] \\
\hline \multirow[t]{3}{*}{ MIGS-22 } & Oxygen requirement & microaerotolerant anaerobic & TAS [6] \\
\hline & Carbon source & glucose & TAS [1] \\
\hline & Energy source & chemoorganotroph & TAS [1] \\
\hline MIGS-6 & Habitat & human gingival crevices & TAS $[1,5]$ \\
\hline MIGS-15 & Biotic relationship & free-living & NAS \\
\hline \multirow[t]{3}{*}{ MIGS-14 } & Pathogenicity & primary endodontic infections & TAS $[11,19,20]$ \\
\hline & Biosafety level & 2 & TAS [21] \\
\hline & Isolation & plaque from human gingival crevices & TAS [1] \\
\hline MIGS-4 & Geographic location & not reported & \\
\hline MIGS-5 & Sample collection time & 1987 or before & TAS $[1,5]$ \\
\hline MIGS-4.1 & Latitude & not reported & \\
\hline MIGS-4.2 & Longitude & not reported & \\
\hline MIGS-4.3 & Depth & not reported & \\
\hline MIGS-4.4 & Altitude & not reported & \\
\hline
\end{tabular}

Evidence codes - IDA: Inferred from Direct Assay (first time in publication); TAS: Traceable Author Statement (i.e., a direct report exists in the literature); NAS: Non-traceable Author Statement (i.e., not directly observed for the living, isolated sample, but based on a generally accepted property for the species, or anecdotal evidence). These evidence codes are from of the Gene Ontology project [22]. If the evidence code is IDA, then the property was directly observed by one of the authors or an expert mentioned in the acknowledgements. 


\begin{tabular}{lll}
\multicolumn{2}{l}{ Table 2. Genome sequencing project information } \\
\hline MIGS ID & Property & Term \\
\hline MIGS-31 & Finishing quality & Finished \\
MIGS-28 & Libraries used & Three genomic libraries: one 454 standard and one \\
MIGS-29 & Sequencing platforms & 454 10 kb pyrosequence library; one Illumina library \\
MIGS-31.2 & Sequencing coverage & 90.5 $\times$ pyrosequence, 211.8× Illumina \\
MIGS-30 & Assemblers & Newbler version 2.0.1-PreRelease-03-30-2009-gcC- \\
MIGS-32 & Gene calling method & Prodigal 1.4, GenePRIMP \\
& INSDC ID & CP002106 \\
& Genbank Date of Release & August 6, 2010 \\
& GOLD ID & Gc01331 \\
& NCBI project ID & 36641 \\
& Database: IMG-GEBA & 2502422319 \\
MIGS-13 & Source material identifier & DSM 7084 \\
& Project relevance & Tree of Life, GEBA \\
\hline
\end{tabular}

\section{Genome sequencing and assembly}

The genome of $O$. uli was sequenced using a combination of Illumina and 454 technologies. An Illumina GAii shotgun library with reads of $434,617,748$ bp, a 454 Titanium draft library with average read length of $302+/-162.3$ bp bases, and a paired end 454 library with average insert size of $9.273+/$ $2.318 \mathrm{~kb}$ were generated. All general aspects of library construction and sequencing can be found at http://www.jgi.doe.gov/. Illumina sequencing data was assembled with VELVET, and the consensus sequences were shredded into $1.5 \mathrm{~kb}$ overlapped fake reads and assembled together with the 454 data. Draft assemblies were based on $2.0 \mathrm{Mb} 454$ draft data, and 454 paired end data. Newbler parameters are -consed -a $50-1350-\mathrm{g}-\mathrm{m}-\mathrm{ml} 20$. The initial Newbler assembly contained 149 contigs in 1 scaffold. We converted the initial 454 assembly into a phrap assembly by making fake reads from the consensus, collecting the read pairs in the 454 paired end library. The Phred/Phrap/Consed software package (www.phrap.com) was used for sequence assembly and quality assessment [35] in the following finishing process. After the shotgun stage, reads were assembled with parallel phrap (High Performance Software, LLC). Possible misassemblies were corrected with gapResolution, Dupfinisher [35], or sequencing cloned bridging PCR fragments with subcloning or transposon bombing (Epicentre Biotechnologies, Madison, WI). Gaps between contigs were closed by editing in Consed, by PCR and by Bubble PCR primer walks (J.-F. Chang, unpublished). A total of 394 additional Sanger reactions were necessary to close gaps and to raise the quality of the finished sequence. Illumina reads were also used to improve the final consensus quality using an in-house developed tool (the Polisher [36], ). The error rate of the final genome sequence is less than 1 in 100,000.

\section{Genome annotation}

Genes were identified using Prodigal [37] as part of the Oak Ridge National Laboratory genome annotation pipeline, followed by a round of manual curation using the JGI GenePRIMP pipeline [38]. The predicted CDSs were translated and used to search the National Center for Biotechnology Information (NCBI) nonredundant database, UniProt, TIGRFam, Pfam, PRIAM, KEGG, COG, and InterPro databases. Additional gene prediction analysis and functional annotation was performed within the Integrated Microbial Genomes - Expert Review (IMG-ER) platform [39].

\section{Genome properties}

The genome consists of a 2,051,896 bp long chromosome with a $64.7 \%$ GC content (Table 3 and Figure 3). Of the 1,850 genes predicted, 1,795 were protein-coding genes, and 55 RNAs; fifty six pseudogenes were also identified. The majority of the protein-coding genes $(75.9 \%)$ were assigned a putative function while the remaining ones were annotated as hypothetical proteins. The distribution of genes into COGs functional categories is presented in Table 4. 
Table 3. Genome Statistics

\begin{tabular}{lrr}
\hline Attribute & Value & \% of Total \\
\hline Genome size (bp) & $2,051,896$ & $100.00 \%$ \\
DNA coding region (bp) & $1,789,074$ & $87.19 \%$ \\
DNA G+C content (bp) & $1,327,526$ & $64.70 \%$ \\
Number of replicons & 1 & \\
Extrachromosomal elements & 0 & \\
Total genes & 1,850 & $100.00 \%$ \\
RNA genes & 55 & $2.97 \%$ \\
rRNA operons & 1 & \\
Protein-coding genes & 1,795 & $97.03 \%$ \\
Pseudo genes & 56 & $3.03 \%$ \\
Genes with function prediction & 1,404 & $75.89 \%$ \\
Genes in paralog clusters & 160 & $8.65 \%$ \\
Genes assigned to COGs & 1,412 & $76.32 \%$ \\
Genes assigned Pfam domains & 1,429 & $77.24 \%$ \\
Genes with signal peptides & 320 & $17.30 \%$ \\
Genes with transmembrane helices & 423 & $22.86 \%$ \\
CRISPR repeats & 1 & \\
\hline
\end{tabular}

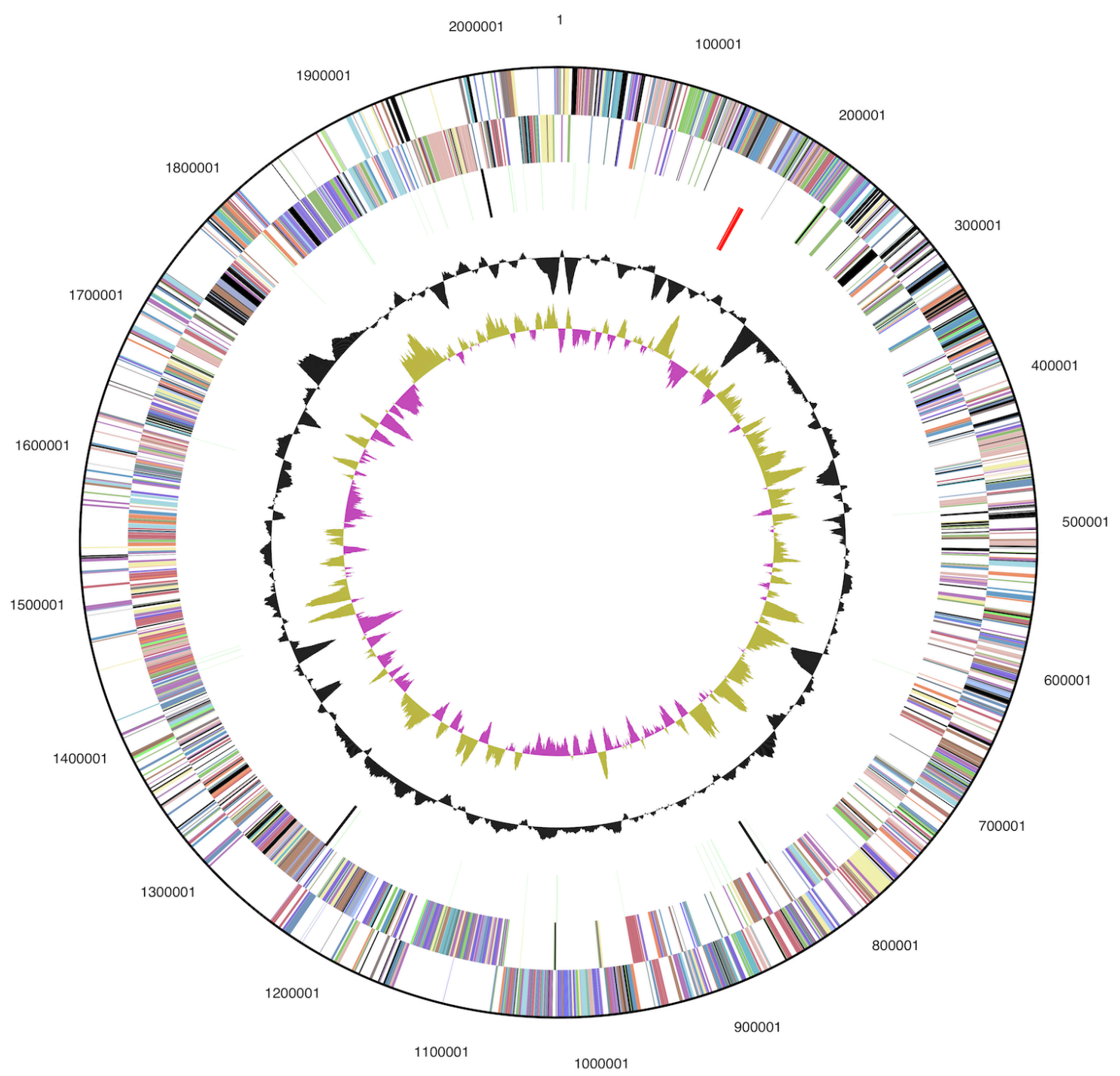

Figure 3. Graphical circular map of the genome. From outside to the center: Genes on forward strand (color by COG categories), Genes on reverse strand (color by COG categories), RNA genes (tRNAs green, rRNAs red, other RNAs black), GC content, GC skew. 
Table 4. Number of genes associated with the general COG functional categories

\begin{tabular}{lrrl}
\hline Code & value & \%age & Description \\
\hline J & 137 & 8.9 & Translation, ribosomal structure and biogenesis \\
A & 0 & 0.0 & RNA processing and modification \\
K & 140 & 9.1 & Transcription \\
L & 82 & 5.3 & Replication, recombination and repair \\
B & 1 & 0.1 & Chromatin structure and dynamics \\
D & 17 & 1.1 & Cell cycle control, cell division, chromosome partitioning \\
Y & 0 & 0.0 & Nuclear structure \\
V & 44 & 2.9 & Defense mechanisms \\
T & 72 & 4.7 & Signal transduction mechanisms \\
M & 86 & 5.6 & Cell wall/membrane/envelope biogenesis \\
N & 0 & 0.0 & Cell motility \\
Z & 0 & 0.0 & Cytoskeleton \\
W & 0 & 0.0 & Extracellular structures \\
U & 18 & 1.2 & Intracellular trafficking, secretion, and vesicular transport \\
O & 51 & 3.3 & Posttranslational modification, protein turnover, chaperones \\
C & 75 & 4.9 & Energy production and conversion \\
G & 165 & 10.7 & Carbohydrate transport and metabolism \\
E & 150 & 9.7 & Amino acid transport and metabolism \\
F & 56 & 3.6 & Nucleotide transport and metabolism \\
H & 46 & 3.0 & Coenzyme transport and metabolism \\
I & 32 & 2.1 & Lipid transport and metabolism \\
P & 66 & 4.3 & Inorganic ion transport and metabolism \\
Q & 24 & 1.6 & Secondary metabolites biosynthesis, transport and catabolism \\
R & 172 & 11.1 & General function prediction only \\
S & 112 & 7.2 & Function unknown \\
- & 438 & 23.7 & Not in COGs \\
\hline
\end{tabular}

\section{Acknowledgements}

We would like to gratefully acknowledge the help of Gabriele Gehrich-Schröter to growing O. uli and Susanne Schneider for DNA extraction and quality analysis (both at DSMZ). This work was performed under the auspices of the US Department of Energy Office of Science, Biological and Environmental Research Program, and by the University of California, Lawrence Berkeley National Laboratory under contract No. DE-
AC02-05CH11231, Lawrence Livermore National Laboratory under Contract No. DE-AC52-07NA27344, and Los Alamos National Laboratory under contract No. DEAC02-06NA25396, UT-Battelle and Oak Ridge National Laboratory under contract DE-AC05-000R22725, as well as German Research Foundation (DFG) INST 599/1-2 and Thailand Research Fund Royal Golden Jubilee Ph.D. Program No. PHD/0019/2548' for MY.

\section{References}

1. Olsen I, Johnson JL, Moore LV, Moore WE. Lactobacillus uli sp. nov. and Lactobacillus rimae sp. nov. from the human gingival crevice and emended descriptions of Lactobacillus minutus and Streptococcus parvulus. Int I Syst Bacteriol 1991; 41:261-266. PubMed doi:10.1099/00207713-41-2-261
2. Euzeby JP. List of Bacterial Names with Standing in Nomenclature: a folder available on the Internet. Int J Syst Bacteriol 1997; 47:590-592. PubMed doi:10.1099/00207713-47-2-590

3. Stackebrandt E, Rainey FA, Ward-Rainey NL. Proposal for a new hierarchic classification system, Actinobacteria classis nov. Int J Syst Bacteriol 
1997; 47:479-491. doi:10.1099/00207713-47-2$\underline{479}$

4. Zhi XY, Li WJ, Stackebrandt E. An update of the structure and $16 \mathrm{~S}$ rRNA gene sequence-based definition of higher ranks of the class Actinobacteria, with the proposal of two new suborders and four new families and emended descriptions of the existing higher taxa. Int I Syst Evol Microbiol 2009; 59:589-608. PubMed doi:10.1099/ijs.0.65780-0

5. Dewhirst FE, Paster BJ, Tzellas N, Coleman B, Downes J, Spratt DA, Wade WG. Characterization of novel human oral isolates and cloned $16 \mathrm{~S}$ rDNA sequences that fall in the family Coriobacteriaceae: description of Olsenella gen. nov., reclassification of Lactobacillus uli as Olsenella uli comb. nov. and description of Olsenella profusa sp. nov. Int J Syst Evol Microbiol 2001; 51:17971804. PubMed

6. Kraatz M, Wallace RJ, Svensson L. Olsenella umbonata sp. nov., a microaerotolerant anaerobic lactic acid bacterium from the sheep rumen and pig jejunum, and emended descriptions of Olsenella, Olsenella uli and Olsenella profusa. Int J Syst Evol Microbiol (In press).

7. Figdor D. Microbial aetiology of endodontic treatment failure and pathogenic properties of selected species. Aust Endod J 2004; 30:11-14. PubMed doi:10.1111/j.17474477.2004.tb00159.x

8. Siqueira JF, Jr. Endodontic infections: concepts, paradigms, and perspectives. Oral Surg Oral Med Oral Pathol Oral Radiol Endod 2002; 94:281-293. PubMed doi:10.1067/moe.2002.126163

9. Copeland A, Sikorski J, Lapidus A, Nolan M, Rio TGD, Lucas S, Chen F, Tice H, Pitluck S, Cheng JF, et al. Complete genome sequence of Atopobium parvulum type strain type strain (IPP $1246^{\top}$ ). Stand Genomic Sci 2009; 1:166-173. doi:10.4056/sigs.29547

10. Rôças IN, Siqueira JF, Jr. Identification of bacteria enduring endodontic treatment procedures by a combined reverse transcriptase-polymerase chain reaction and reverse-capture checkerboard approach. J Endod 2010; 36:45-52. PubMed doi:10.1016/j.joen.2009.10.022

11. Siqueira JF, Jr., Rocas IN. Uncultivated phylotypes and newly named species associated with primary and persistent endodontic infections. J Clin Microbiol 2005; 43:3314-3319. PubMed doi:10.1128/JCM.43.7.3314-3319.2005
12. Hooper SJ, Crean SJ, Lewis MA, Spratt DA, Wade WG, Wilson MJ. Viable bacteria present within oral squamous cell carcinoma tissue. J Clin Microbiol 2006; 44:1719-1725. PubMed doi:10.1128/JCM.44.5.1719-1725.2006

13. Benson DA, Karsch-Mizrachi I, Lipman DJ, Ostell J, Sayers EW. GenBank. Nucleic Acids Res 2009; 37:D26-D31. PubMed doi:10.1093/nar/gkn723

14. Chun J, Lee JH, Jung Y, Kim M, Kim S, Kim BK, Lim YW. EzTaxon: a web-based tool for the identification of prokaryotes based on $16 \mathrm{~S}$ ribosomal RNA gene sequences. Int I Syst Evol Microbiol 2007; 57:2259-2261. PubMed doi:10.1099/ijs.0.64915-0

15. Field D, Garrity G, Gray T, Morrison N, Selengut J, Sterk P, Tatusova T, Thomson N, Allen MJ, Angiuoli $\mathrm{SV}$, et al. The minimum information about a genome sequence (MIGS) specification. Nat Biotechnol 2008; 26:541-547. PubMed doi:10.1038/nbt1360

16. Woese CR, Kandler O, Wheelis ML. Towards a natural system of organisms: proposal for the domains Archaea, Bacteria, and Eucarya. Proc Natl Acad Sci USA 1990; 87:4576-4579. PubMed doi:10.1073/pnas.87.12.4576

17. Garrity GM, Holt JG. The Road Map to the Manual. In: Garrity GM, Boone DR, Castenholz RW (eds), Bergey's Manual of Systematic Bacteriology, Second Edition, Volume 1, Springer, New York, 2001, p. 119-169.

18. Garrity GM, Bell JA, Lilburn T. Taxonomic outline of the Procaryotes. In: Garrity GM, Bell JA, Lilburn TG (eds), Taxonomic Outline of the Procaryotes, Bergey's Manual of Systematic Bacteriology, Second Edition. Release 4.0, Fourth Edition, Springer-Verlag, New York, 2003, p. 1-39.

19. Chávez de Paz LE, Molander A, Dahlen G. Grampositive rods prevailing in teeth with apical periodontitis undergoing root canal treatment. Int Endod I 2004; 37:579-587. PubMed doi:10.1111/j.1365-2591.2004.00845.x

20. Rôças IN, Siqueira JF, Jr. Detection of novel oral species and phylotypes in symptomatic endodontic infections including abscesses. FEMS Microbiol Lett 2005; 250:279-285. PubMed doi:10.1016/j.femsle.2005.07.017

21. Classification of bacteria and archaea in risk groups. http://www.baua.de TRBA 466.

22. Ashburner M, Ball CA, Blake JA, Botstein D, Butler $\mathrm{H}$, Cherry JM, Davis AP, Dolinski K, Dwight SS, Eppig JT, et al. Gene Ontology: tool for the 
unification of biology. Nat Genet 2000; 25:25-29. $\underline{\text { PubMed doi:10.1038/75556 }}$

23. DSMZ Catalogue of Strains. (2001), Seventh Edition.

24. Castresana J. Selection of conserved blocks from multiple alignments for their use in phylogenetic analysis. Mol Biol Evol 2000; 17:540-552. PubMed

25. Lee C, Grasso C, Sharlow MF. Multiple sequence alignment using partial order graphs. Bioinformatics 2002; 18:452-464. PubMed doi:10.1093/bioinformatics/18.3.452

26. Stamatakis A, Hoover $\mathrm{P}$, Rougemont J. A rapid bootstrap algorithm for the RAxML Web servers. Syst Biol 2008; 57:758-771. PubMed doi:10.1080/10635150802429642

27. Yarza P, Richter M, Peplies J, Euzeby J, Amann R, Schleifer KH, Ludwig W, Glöckner FO, RossellóMóra R. The All-Species Living Tree project: A $16 \mathrm{~S}$ rRNA-based phylogenetic tree of all sequenced type strains. Syst Appl Microbiol 2008; 31:241-250. PubMed doi:10.1016/j.syapm.2008.07.001

28. Pattengale ND, Alipour M, Bininda-Emonds ORP, Moret BME, Stamatakis A. How many bootstrap replicates are necessary? Lect Notes Comput Sci 2009; 5541:184-200. doi:10.1007/978-3-642$\underline{02008-7 \quad 13}$

29. Liolios K, Chen IM, Mavromatis K, Tavernarakis N, Hugenholtz P, Markowitz VM, Kyrpides NC. The Genomes On Line Database (GOLD) in 2009: status of genomic and metagenomic projects and their associated metadata. Nucleic Acids Res 2009; 38:D346-D354. PubMed doi:10.1093/nar/gkp848

30. Saunders E, Pukall R, Abt B, Lapidus A, Glavina Del Rio T, Copeland A, Tice H, Cheng JF, Lucas $\mathrm{S}$, Chen $\mathrm{F}$, et al. Complete genome sequence of Eggerthella lenta type strain (VPI $0255^{\mathrm{T}}$ ). Stand Genomic Sci 2009; 1:174-182. doi:10.4056/sigs.33592
31. Mavromatis K, Pukall R, Rohde C, Chen F, Sims D, Brettin T, Kuske C, Detter JC, Han C, Lapidus $\mathrm{A}$, et al. Complete genome sequence of Cryptobacterium curtum type strain $\left(12-3^{\top}\right)$. Stand Genomic Sci 2009; 1:93-100. doi:10.4056/sigs. 12260

32. Klenk HP, Goeker M. En route to a genome-based classification of Archaea and Bacteria? Syst Appl Microbiol 2010; 33:175-182. PubMed doi:10.1016/j.syapm.2010.03.003

33. Wu D, Hugenholtz P, Mavromatis K, Pukall R, Dalin E, Ivanova NN, Kunin V, Goodwin L, Wu $M$, Tindall BJ, et al. A phylogeny-driven genomic encyclopaedia of Bacteria and Archaea. Nature 2009; 462:1056-1060. PubMed doi:10.1038/nature08656

34. List of growth media used at DSMZ: http//www.dsmz.de/microorganisms/media_list.p hp.

35. Sims D, Brettin T, Detter JC, Han C, Lapidus A, Copeland A, Glavina Del Rio T, Nolan M, Chen $\mathrm{F}$, Lucas $\mathrm{S}$, et al. Complete genome sequence of Kytococcus sedentarius type strain $\left(541^{\top}\right)$. Stand Genomic Sci 2009; 1:12-20. doi:10.4056/sigs.761

36. Lapidus A, LaButti K, Foster B, Lowry S, Trong S, Goltsman E. POLISHER: An effective tool for using ultra short reads in microbial genome assembly and finishing. AGBT, Marco Island, FL, 2008.

37. Hyatt D, Chen GL, Locascio PF, Land ML, Larimer FW, Hauser LJ. Prodigal: prokaryotic gene recognition and translation initiation site identification. BMC Bioinformatics 2010; 11:119. PubMed doi:10.1186/1471-2105-11-119

38. Pati A, Ivanova NN, Mikhailova N, Ovchinnikova G, Hooper SD, Lykidis A, Kyrpides NC. GenePRIMP: a gene prediction improvement pipeline for prokaryotic genomes. Nat Methods 2010; 7:455-457. PubMed doi:10.1038/nmeth.1457

39. Markowitz VM, Ivanova NN, Chen IMA, Chu K, Kyrpides NC. IMG ER: a system for microbial genome annotation expert review and curation. Bioinformatics 2009; 25:2271-2278. PubMed doi:10.1093/bioinformatics/btp393 